\title{
Improvement of multicrystalline silicon wafer solar cells by post-fabrication wet-chemical etching in phosphoric acid
}

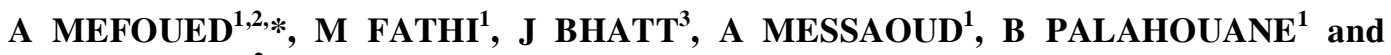 \\ N BENREKAA ${ }^{2}$ \\ ${ }^{1}$ Silicon Technology Unit (UDTS), 02 Bd Frantz Fanon, BP. 140, Alger-7 Merveilles, Algiers, Algeria \\ ${ }^{2}$ Houari Boumediene University of Science and Technology (USTHB), Bab Ezzouar, Algiers, Algeria \\ ${ }^{3}$ SSN-Research Centre, Rajiv Gandhi Salai (OMR), Kalavakkam 603 110, India
}

MS received 2 May 2010

\begin{abstract}
In this study, we have improved electrical characteristics such as the efficiency $(\eta)$ and the fill factor (FF) of finished multicrystalline silicon ( $m c$-Si) solar cells by using a new chemical treatment with a hot phosphoric $\left(\mathrm{H}_{3} \mathrm{PO}_{4}\right)$ acidic solution. These $m c$-Si solar cells were made by a standard industrial process with screen-printed contacts and a silicon nitride ( $\mathrm{SiN})$ antireflection coating. We have deposited SiN thin layer $(80 \mathrm{~nm})$ on $p$-type $m c$-Si substrate by the mean of plasma enhanced chemical vapour deposition (PECVD) technique. The reactive gases used as precursors inside PECVD chamber are a mixture of silane $\left(\mathrm{SiH}_{4}\right)$ and ammonia $\left(\mathrm{NH}_{3}\right)$ at a temperature of $380^{\circ} \mathrm{C}$. The developed $\mathrm{H}_{3} \mathrm{PO}_{4}$ chemical surface treatment has improved $\eta$ from 5.4 to $7.7 \%$ and FF from 50.4 to $\mathbf{7 0 . 8 \%}$, this means a relative increase of up to $40 \%$ from the initial values of $\eta$ and FF. In order to explain these improvements, physical (AFM, EDX), chemical (FTIR) and optical (spectrophotometer) analyses were done.
\end{abstract}

Keywords. Silicon; PECVD; passivation; AFM; $\mathrm{H}_{3} \mathrm{PO}_{4}$ etch.

\section{Introduction}

Silicon nitride $(\mathrm{SiN})$ thin films are widely used in various microelectronic and optoelectronic devices (Ino et al 1994). It is used as gate dielectric in MOS components (Tsividis 1999) and also applied in the fabrication of microelectromechanical systems (MEMS) (Kaushik et al 2005). In photovoltaic field, $\mathrm{SiN}$ has the function of defects passivation (Sopori et al 1996) and light antireflection (Barreraa et al 2008). $\mathrm{SiN}$ is applied as antireflective coating (ARC) to minimize reflections and ensuring a higher photocurrent (El Amrani et al 2008). It is also known that the hydrogen introduced in SiN film has a crucial role in the bulk and surface passivation (Duernickx and Szlufck 2002; Sopori et al 2005). Generally, for solar cells metallization a standard screen printing process is applied. Initially, this process was first developed for monocrystalline silicon solar cells and then adapted for multicrystalline silicon substrate. The application of this process on $m c$-Si wafers results in lower performance solar devices. A classical hydrofluoric acid (HF) dipping is well known for enhancing the efficiency $(\eta)$ and the fill factor (FF) and for long time was applied on monocrystalline silicon solar cells. Unfortunately, HF immersion was found to be less effective in enhancing

*Author for correspondence (amefoued@ hotmail.com) the electrical characteristics ( $\eta$ and FF) of the $m c$-Si solar cells. By contrast, we show in this paper that we can boost $m c$-Si solar cells performances with our new and cost effective chemical $\mathrm{H}_{3} \mathrm{PO}_{4}$ treatment.

\section{Experimental}

Solar cells used in this study were based on structure of $n^{+} / p$ junction. The structure of this $n^{+} / p$ multicrystalline silicon cell is given in figure 1 .

The starting material was a $m c$-Si wafer of $p$-type (boron-doped) with $\sim 3 \Omega \mathrm{cm}$ resistivity and having an initial thickness of $380 \mu \mathrm{m}$. These wafers were dipped into $\mathrm{NaOH}\left(30 \%\right.$ at $\left.85^{\circ} \mathrm{C}\right)$ polishing solution until a final thickness of $350 \mu \mathrm{m}$ was reached; followed neutralization and RCA decontamination stages by putting them in a bath made of $\mathrm{H}_{2} \mathrm{O}_{2} / \mathrm{NH}_{4} \mathrm{OH} / \mathrm{DI} \mathrm{H}_{2} \mathrm{O}$ at $70^{\circ} \mathrm{C}$, then etched in diluted $\mathrm{HF}(5 \%)$ immediately (Kern and Puotinen 1970)

We started by the diffusion of $n$ donor atoms (phosphor) made by a gas source of $\mathrm{POCl}_{3}$ mixed with oxygen $\left(\mathrm{O}_{2}\right)$ gas and injected into a $\mathrm{LYDOP}^{\circledR}$ furnace tube at $875^{\circ} \mathrm{C}$, leading to $40 \Omega / \square$ emitter resistance, thus conducting to a shallow $n^{+}$junction with about $2.7 \times 10^{20} \mathrm{~cm}^{-3}$ doping. For the device to function well, elimination of $n^{+}$diffusion on lateral sides of solar cells was necessary. A plasma etching was made to remove the parasitic junc- 
tion. Phosphor silicon glass (PSG) layer resulting from the diffusion step was removed by dipping in diluted HF (10\%) solution. The next step was the deposition of $\mathrm{SiN}$ thin film by PECVD technique (SEMCO Engineering furnace). We used an industrial low frequency (LF) direct plasma pulsed reactor operating at $430 \mathrm{kHz}$ using a gas mixture of silane $\left(\mathrm{SiH}_{4}\right)$ and ammonia $\left(\mathrm{NH}_{3}\right)$. Finally, $\mathrm{Ag}$ and $\mathrm{Ag}-\mathrm{Al}$ paste screen printing contacts on the front and back sides, respectively were done. The front contact consisted of a grid formed by parallel strip lines connected to 2 busbars. The back contact was a uniform layer of $\mathrm{Ag}-\mathrm{Al}$ composite covering the whole $m c$-Si surface. The purpose of using an Ag/Al mixture paste was to eliminate the backside parasitic $n^{+}$junction. A firing step with a BTU furnace was applied in order to allow diffusion of $\mathrm{Ag}$ front contact through the $\mathrm{SiN}$ layer (known as firing through process). Also, this firing step permitted the diffusion of $\mathrm{Ag} / \mathrm{Al}$ paste in the back side of $m c-\mathrm{Si}$ wafer and gave a good ohmic contact. The obtained cells were tested under normalized conditions of AM1.5 $\left(1000 \mathrm{~W} / \mathrm{m}^{2}\right)$ by a Fraunhofer $I-V$ solar simulator to extract the electrical parameters. Then, these cells were etched in $\mathrm{H}_{3} \mathrm{PO}_{4}$ solution and we extracted the new electrical parameters ( $\eta$ and FF) by $I-V$ measurement.

The thickness of SiN layer was determined by ellipsometry (EL X-1, Dr Riss Ellipsometer bau GmbH). The reflectance was measured using a Varian Cary 500 UVVIS-NIR spectrophotometer. The chemical etch was done by an acidic solution of $\mathrm{H}_{3} \mathrm{PO}_{4}(68 \%)$ at a temperature of $85^{\circ} \mathrm{C}$. In order to study the influence of $\mathrm{H}_{3} \mathrm{PO}_{4}$ solution in passivating both $\mathrm{SiN} / \mathrm{Si}$ interface and $\mathrm{Si}$ bulk, several samples were etched at two different times of 20 and $30 \mathrm{~min}$. The conditions of $\mathrm{SiN}$ deposition inside PECVD chamber are summarized in table 1.

\section{Results and discussion}

The $\mathrm{H}_{3} \mathrm{PO}_{4}$ treatment was applied to $n^{+} / p$ standard solar cell that has been realized by the process described above. Conceding that, the initial efficiency $(\eta)$ and fill factor (FF) were as low as $5.4 \%$ and $50.4 \%$, respectively

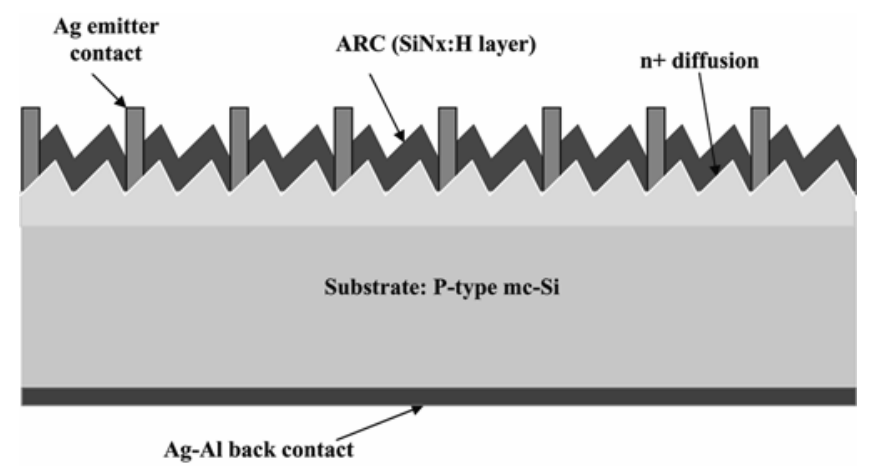

Figure 1. Schematic view of $m c-S i n^{+} / p$ photovoltaic device. for sample S1. Nevertheless, after $\mathrm{H}_{3} \mathrm{PO}_{4}$ treatment for $30 \mathrm{~min}$ at $85^{\circ} \mathrm{C}$, we observed an improvement of $\eta$ and $\mathrm{FF}$ as shown in figure 2 . The $\eta$ reached $7.7 \%$ and $\mathrm{FF}$ $70.8 \%$, this means a relative increase of about $40 \%$ up from the initial values. In order to demonstrate the reproducibility of this process we have etched a second sample (S2). Figure 3 shows the amelioration of $\eta$ and FF. For

Table 1. PECVD parameters for SiN deposition on $m c-\mathrm{Si}$ substrate.

\begin{tabular}{lc}
\hline PECVD parameters & Parameter values \\
\hline Temperature inside the chamber & $380^{\circ} \mathrm{C}$ \\
Gases ratio $\mathrm{SiH}_{4} / \mathrm{NH}_{3}$ & $1 / 6$ \\
Deposition time & $150 \mathrm{~s}$ \\
Film thickness & $80 \mathrm{~nm}$ \\
Pressure & $1700 \mathrm{mTorr}$ \\
\hline
\end{tabular}

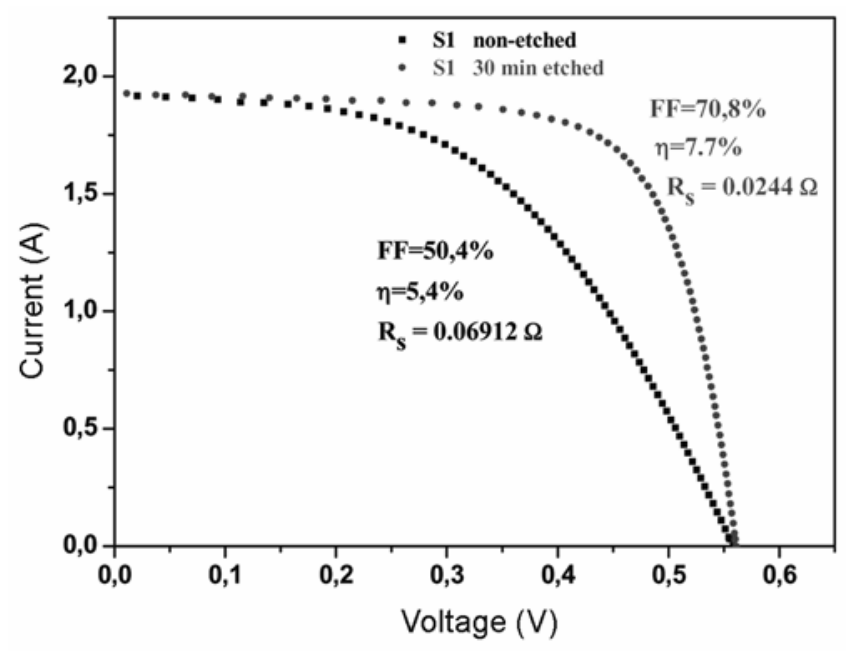

Figure 2. $I-V$ of $\mathrm{S} 1$ solar cell.

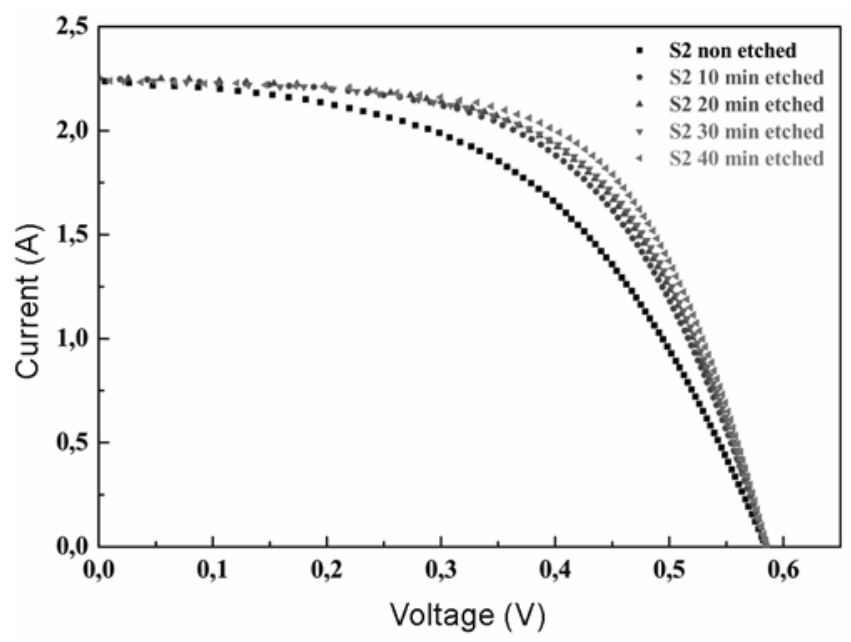

Figure 3. $I-V$ of $\mathrm{S} 2$ solar cell. 


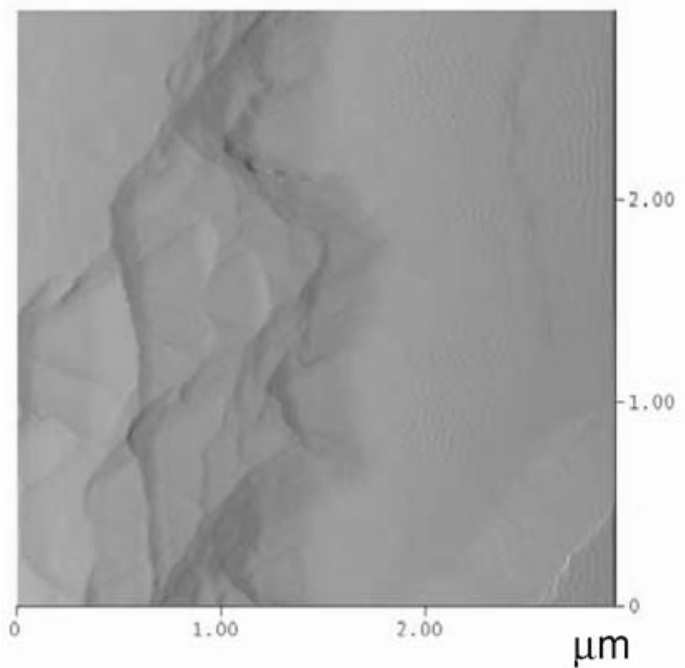

SiN/Si: Roughness $=473 \mathrm{~nm}$

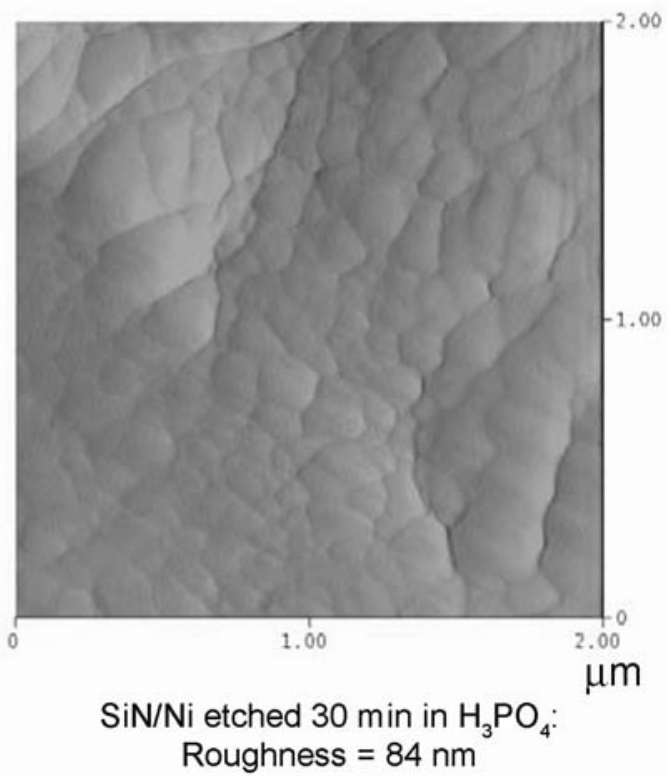

Figure 4. AFM view of SiN surface.
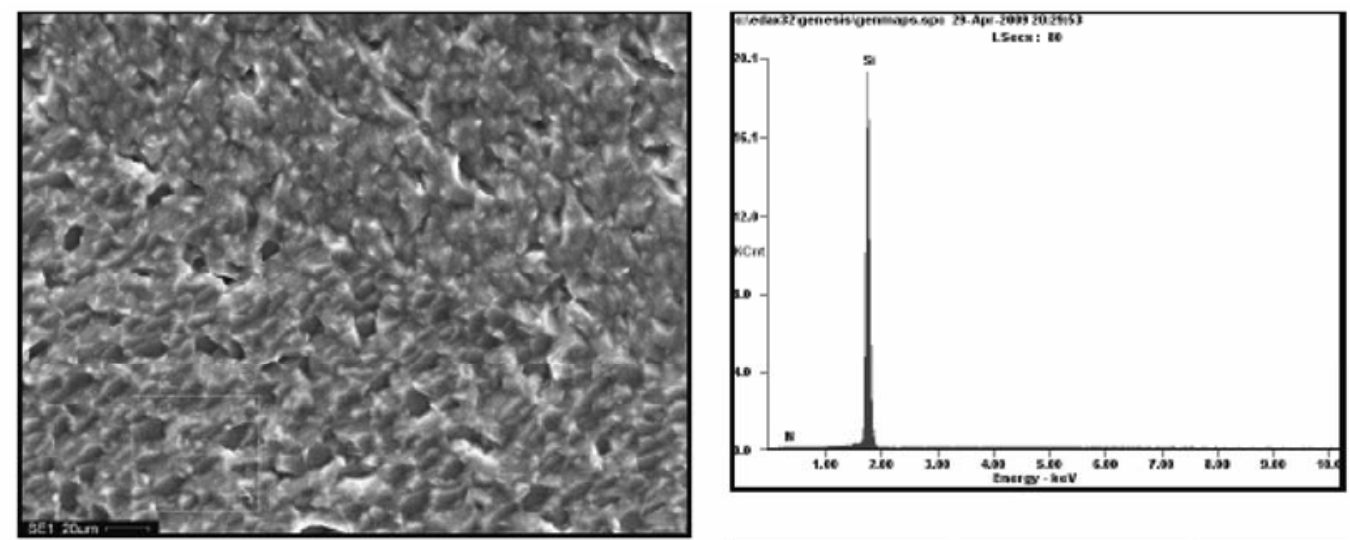

\begin{tabular}{|c|l|l|}
\hline Element & $\boldsymbol{W t} \%$ & $\boldsymbol{A} \boldsymbol{t}^{\boldsymbol{0}} \%$ \\
\hline $\boldsymbol{N} \boldsymbol{K}$ & 05.65 & 10.71 \\
\hline SiK & 94.35 & 89.29 \\
\hline
\end{tabular}

Figure 5. SEM-EDX analysis of $\mathrm{SiN}$ thin layer etched by $\mathrm{H}_{3} \mathrm{PO}_{4}$ for $30 \mathrm{~min}$.

the S2 solar cell, we have chosen the etching times: 10, 20, 30 and $40 \mathrm{~min}$. Series resistance was calculated and found to be decreasing after chemical attack as shown in figure 2. In order to understand the physics behind the boosting of $\eta$ and FF, we made a full analysis of the chemical composition of $\mathrm{SiN}$ thin layer before and after etching.

Our first interpretation of the roughness evolution by atomic force microscopy (AFM) analysis (figure 4) is that the final roughness of $84 \mathrm{~nm}$ is equal to the thickness of $\mathrm{SiN}$ layer $(80 \mathrm{~nm})$. This means that the layer is starting to be locally etched and more preferentially at grain boundaries, which facilitates the acidic solution penetration to the SiN/Si interface. Thus, the passivation by hydrogenation becomes more probable.

On the other hand, we have done the SEM-EDX analysis. We found that following the chemical etch by $\mathrm{H}_{3} \mathrm{PO}_{4}$ solution, the $\mathrm{Si}$ content of $\mathrm{SiN}$ layer increases. Figure 5 shows SEM micrograph and EDX analysis of a $30 \mathrm{~min}$ etched sample. Figure 6 summarizes all SEM-EDX studies for grain regions i.e. small grain, large grain and grain boundaries. We found that in the small grain region the $\mathrm{SiN}$ layer is Si rich. The explanation to this phenomenon is that for the small grain region, the density of grain boundaries and crystalline defects becomes higher and the number of free $\mathrm{Si}$ pending bonds increases (on the 
$m c$-Si substrate). This facilitates the $\mathrm{Si}$ atoms fixation during PECVD SiN deposition in these regions which leads to a Si rich area. Globally (as shown in figure 6), etching in $\mathrm{H}_{3} \mathrm{PO}_{4}$ solution for $30 \mathrm{~min}$ increases the $\mathrm{Si}$ content in all regions (small grains, large grains and grain boundaries) of $m c-\mathrm{Si}$ wafer and thus ameliorating the passivation effect. Also, the PECVD SiN deposition process is accomplished with a relatively high ration of $\mathrm{SiH}_{4} / \mathrm{NH}_{3}$ gas and these lead to a $\mathrm{Si}$ rich thin $\mathrm{SiN}$ layer (Sopori 2003).

The $\mathrm{H}_{3} \mathrm{PO}_{4}$ etch leads to an increase of $\mathrm{Si}$ content in all regions (small grain, large grain and grain boundaries) of the SiN layer as shown in figure 6. This can explain observed $I(V)$ and improved electrical performances of the solar cells (figures 2 and 3 ).

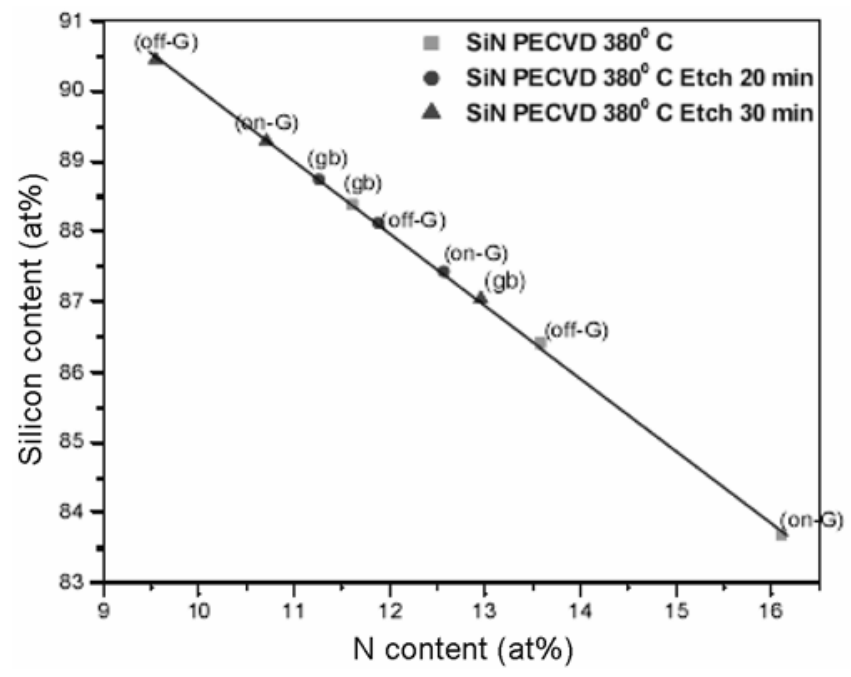

Figure 6. N/Si content with different $\mathrm{H}_{3} \mathrm{PO}_{4}$ etching times.

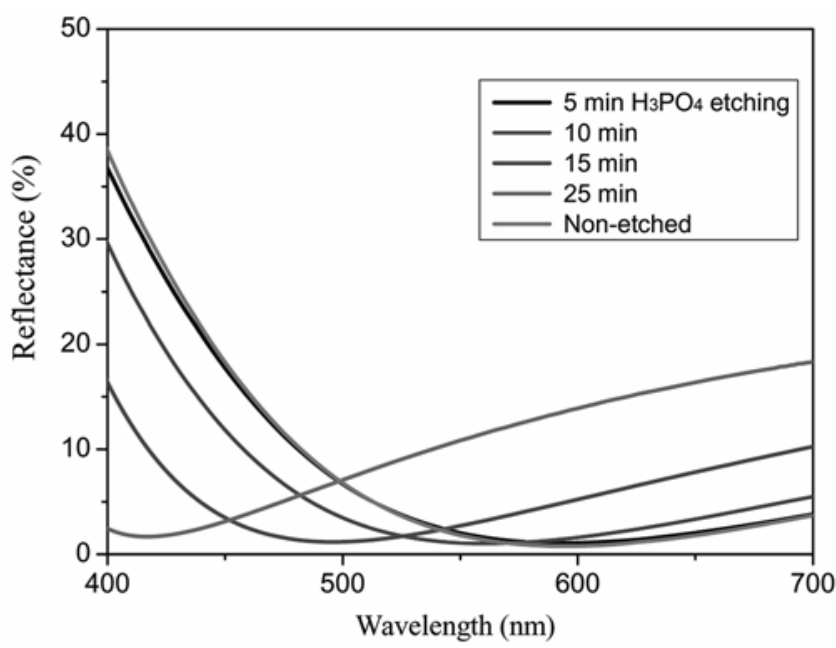

Figure 7. Reflectance of SiN coated solar cells.
Finally, we used a Varian Cary 500 spectrophotometer to extract the reflectance of thin $\mathrm{SiN}$ layer. The reflectance was measured for each of the samples that were etched for different times. We can see from figure 7 that a non-etched $\mathrm{SiN}$ layer is highly reflective in the visible range as well as the near-UV. In contrast, the sample etched for $25 \mathrm{~min}$ displays a low reflectance behaviour in the near-UV range. The sample etched for $15 \mathrm{~min}$ in $\mathrm{H}_{3} \mathrm{PO}_{4}$ possesses the best reflective characteristics in the 400-700 $\mathrm{nm}$ range i.e. it absorbs more light than the other samples on a broader spectral array.

\section{Conclusions}

We have shown an effective amelioration of $I(V)$ characteristics resulting from a new $\mathrm{H}_{3} \mathrm{PO}_{4}$ chemical treatment. A boosting up to $40 \%$ of efficiency and fill factor has been successfully accomplished by this treatment. AFM study shows that $\mathrm{SiN}$ layer is starting to be locally etched after $30 \mathrm{~min}$ of $\mathrm{H}_{3} \mathrm{PO}_{4}$ etch which facilitates the acidic solution penetration to the SiN/Si interface. Thus, the passivation by hydrogenation becomes more probable. Finally, SEM-EDX study showed that after this chemical treatment, the rate of $\mathrm{Si}$ content increases in all regions (small grains, large grains and grain boundaries) of the $\mathrm{SiN}$ thin layer and thus ameliorating the passivation effect. Phosphoric acid passivation is an effective way to make a better passivation of $\mathrm{SiN} / m c$-Si interface at low temperature.

\section{References}

Barreraa M, Pláa J, Bocchib C and Miglioric A 2008 Sol. Energy Mater. Sol. Cells 921115

Duernickx F and Szlufck J 2002 Sol. Energy Mater. Sol. Cells 72231

El Amrani A, Menous I, Mahiou L, Tadjine R, Touati A and Lefgoum A 2008 Renew. Energ. 332289

Ino M, Inoue N and Yoshimaru M 1994 Trans. Electron Dev. 41703

Kaushik A, Kahn H and Heuer A H 2005 J. Microelectromech. Syst. 14359

Kern W and Puotinen D A 1970 RCA Rev. 187

Sopori B 2003 J. Electron. Mater. 321034

Sopori B L, Deng X, Benner J P, Rohatgi A, Sana P, Estreicher S K, Park Y K and Robertson M A 1996 Sol. Energy Mater. Sol. Cells 41/42 159

Sopori B, Zhang Y, Reedy R, Jones K, Yan Y, Al-Jassim M M, Bathey B and Kalejs J 2005 Proc. 31st IEEE photovoltaic specialist conference, Florida (New York: IEEE) pp. 1039-1042

Tsividis Y 1999 Operation and modeling of the MOS transistor (McGraw-Hill) 2nd edn 